\title{
Habitar a escuridão: materialidades negras, 0 olho e a quebra
}

\author{
José Juliano Gadelha ${ }^{1}$
}

Resumo: Este artigo visa pensar, através de uma série de questões recorrentes e sobrepostas, o status do visível em relação à reflexividade; a captura e a captação dos signos; a violência mimética em suas teias de dor e perdão; e o lugar da arte na produção de redes cósmicas e tecnologias ancestrais.

Palavras-chave: Imagem; Olho; Quebra; Visual.

\section{Dwelling The Darkness: Black Materialities, The Eye And The Break}

\begin{abstract}
This article aims to think through a series of recurring and overlapping questions, such as the status of the visible in relation to reflexivity; the capture of signs; the mimetic violence in its pain and forgiveness webs; and the place of art in the production of cosmic networks and ancestral technologies.
\end{abstract}

Keywords: Image; Eye; Break; Visual.

Gadelha, J. J.

1 Artista e escritor nascido em Fortaleza, CE. Mestre em Artes pelo Instituto de Cultura e Artes da Universidade Federal do Ceará (ICA - UFC), mestre em Sociologia pelo Programa de Pós-Graduação em Sociologia da Universidade Federal do Ceará (PPGS - UFC). E-mail: jjulianogadelha@gmail.com. ORCID: http://orcid.org/0000-0001-55072376. Lattes iD: http://lattes.cnpq.br/8121588606751352. Pelotas, Rio Grande do Sul. 
O olho não é apenas espelho, mas espelho retificador. O olho deve nos permitir corrigir os erros culturais. Não estou falando dos olhos, estou falando do olho, e sabe-se a que este olho nos conecta; não à fissura calcária, mas a este clarão constante que surge do vermelho de Van Gogh, que flui de um concerto de Tchaikowsky, que se agarra desesperadamente à ode à la joie de Schiller, que se deixa levar pelo berro vermiforme de Césaire. ${ }^{1}$

\section{Introdução}

Para além de um cruzamento, de coisas mantidas juntas ou colocadas umas sobre as outras na proximidade e na semelhança, questiono como a visão é instaurada no trato da percepção e da sensação com as imagens em encontros que não são necessariamente definidos pela totalidade ou pelas partes, tampouco definidos pela singularidade e/ou pela diferença. Que tipos de visibilidades podem ser concebíveis, ao mesmo tempo, através da quebra $^{2}$ e de certa comunhão com o universo?

Compreendo a visibilidade como imagem e também conhecimento do visível e do invisível. Talvez possamos compreendê-la como dispositivo, desde que essa noção de dispositivo não se resuma a efeitos discursivos, tampouco a certa performatividade entre corpos e linguagem. A visibilidade mesma, aquela produzida nas camadas mais profundas do neoliberalismo, destoa de ser mero efeito da história das tecnologias modernas. Há, por todo planeta, cosmovisões acerca da reflexividade e da sensorialidade das imagens, em que imagens são tomadas como toda materialidade capaz de exibir, conjurar, fraturar, esconder e expandir as forças da visão. No entanto, a visão tende a ser outro conceito complexo, para não dizer problemático, porque tendemos a fechá-lo à capacidade ótica dos olhos em sua mediação com as gramáticas da cultura e com os aparatos técnicos, científicos, estéticos e de outras relações sociais. Esquecemos facilmente do olho que fabricamos ou daquele olho que se fabrica mesmo à nossa revelia e até mesmo contra as nossas próprias convicções mais apaixonadas.

2 A quebra não é uma categoria ordenada, e, sim, uma força abrupta de corte e expansão múltiplas. Ela diz das próprias forças cósmicas de criação, destruição e recriação infinitas e implicadas do universo em seus múltiplos universos. Essa força abrupta se manifesta também na ruptura dos ordenamentos do mundo tal como o conhecemos. 


\section{O olho}

O olho se move por meio da interrupção com o imediatamente visto que as imagens efetivam. Esse movimento corta e aumenta o visual. Ele ocorre nas materialidades negras ${ }^{3}$ por uma reavaliação ou reconstrução de valor do signo, uma força que perturba as oposições do ver e ser visto, do corpo e do espírito. Ultrapassamos aí a cisão do olhar em que o que vemos e o que nos olha sai das fissuras da representação e da subjetividade, porque a reposta a esse jogo da cisão vem sempre como resposta apaixonada ${ }^{4}$. A tese de uma possível oscilação entre quaisquer polos ou binarismos é sabotada, a todo momento, pelo rebobinar das vidas tornadas negras em sua última e em sua primeira quebra, ambas repetidas nas imagens. Não é o caso de uma falha que põe em xeque polos de referência e de agência do visual, mas sim de quebras e falhas que atualizam sempre a nova quebra pela primeira, sem o princípio de originalidade e com o princípio de uma ontologia negada aos mundos negros. Estes mundos costumam voltar como insolência, recusa ou simplesmente negligência ao risco ontológico do Branco, o qual sempre busca onde continua e onde se quebra o ver e o visto. Isso também não permite uma nova linha extragenética como a de um destino das imagens, se tentarmos pensar a partir de algum trajeto fenomenológico. $\mathrm{O}$ destino das matérias negras ocorre como rota de fuga contrária à negação de suas vidas. Trata-se de um destino que não obedece à flecha do tempo. Quando essa negação parte das redes visuais, as imagens negras só existem em débito com a própria capacidade do ver das imagens e do que estas últimas, via futurismo estético dos modos de governança, empurram àquelas materialidades. Diante da negação do visível, as materialidades negras forjam seu olho quando devoram o próprio visível, instaurando o invisível que vê, mas que só pode ser visto quando os olhos atravessam os fantasmas sem prender a vibração das imagens à própria oscilação espectral. Isso não concerne ao invisível como simplesmente o que teria uma força de não ser visto, mas àquilo que foi impedido de olhar e de ser visto em uma ontologia negada. Assim, a matéria negra produz o jamais visto ainda que

3 Tomo as noções de negro/negra/negritude em relação às vidas matizadas pela escuridão, tais como as pretitudes que, dentre outras coisas, dizem das diversas possibilidades das gentes de cor preta em habitar a negritude, significando-a de outras maneiras, uma significação só possível pelas gentes que foram designadas de forma racista como O Negro pelo Branco. Por isso, as palavras negro(s), negra(s) e negritude(s) estarão sempre em itálico. Além disso, uso a palavra Negro com inicial maiúscula nos momentos em que ressalto como essa personagem foi construída em uma espécie de jogo do espelho, como sendo a negação do Branco.

4 Desvinculo-me das ontologias que não ultrapassam a cisão do olhar, tão comuns em mapeamentos psicanalíticos e filosóficos eurocêntricos. 
a olhemos constantemente. De onde vem essa força de não calcar a visão na equação visual da subtração de vidas inteiras?

A ocasião para a instauração do olho das vidas empurradas à subtração é a entrada em que a questão do ver e da escuridão convergem. O olho denuncia o que vemos e o que nos rouba, deslocando a visão de conquista (abstrata/reflexiva), rumo a uma nova luminosidade de forças que renuncia toda clarificação. O olho se faz na passagem incerta pelas nossas sombras sem ficar refém dos espectros. A forma profética das imagens no instante mesmo em que as olhamos e não o seu destino ordenado que importa. Significa instaurar o olho criminal das cores, formas e sensações, deixando a matéria existir em seu poder de gerar mais matéria. A profundidade e a perspectiva são sempre a de algum crime à governança do mundo, responsável por prender o sensível a certa experiência subjetiva. Aí a vanguarda, se pensarmos por esse termo, só pode existir como uma vanguarda sentimental, melodicamente impossível de habitar; se não estamos na profecia da coisa vista, ao mesmo tempo, é uma vanguarda fraternal que acolhe todos e todas de sua profecia. O olho explode sempre como iniciado e somente os olhos de alguma comunidade criminal para ver o olho ou forjar algum olho. Essa vanguarda funciona por características disruptivas de tudo que a modernidade nos diz. Isso não significa que haja algum fechamento engajado, pois a obra negra foi forjada sob as forças mais viciosas da modernidade e devolve à turbulência moderna a força criativa do que ela despedaça: o grito do silêncio, a volta das gentes exiladas, o sítio pelas que foram sitiadas, as premonições de quem teve seu futuro negado. O melódico difere de ser uma questão romantizada; ele consiste na criação radical, em nossas camadas de vulnerabilidade, falha, desespero, dor e de outras violências sofridas para que fujamos de toda miséria de imaginário, presa à autorreferencialidade da subtração de nossas vidas. O melódico também diz de onde a chamada experiência subjetiva se reencontra com o cosmos, sem fazer o sentido dele determinado por ela.

Não fazemos apenas estética. Estamos em premonição com traços, sons, imagens etc. O confronto vem daí, mas ele não consiste na força que nos move. O que podemos gerar é o que nos interessa. Há vida em nós, mesmo estando abaixo de toda superfície. Então, cavamos algum túnel sempre em direção ao futuro dessa história e ao que ela poderá gerar, independente da possibilidade libertadora que possa conter e ativar. Os impulsos pelos quais somos gentes animadas e percebidas umas pelas outras e umas nas outras compõem uma não convergência entre os significados de nossas produções. O significado, qualquer que seja, se torna inoperante pela oposição entre totalidade e singularidade, tanto quanto ele é inoperante como 
unidade que nos agenciaria como uma mesma coisa. No corte dessa oposição, há um lugar de conjunto, uma poética do "em comum" que não é feita pela soma das ideias e/ou das pessoas envolvidas, mas sim onde podemos reexistir de muitas maneiras ou, simplesmente, podemos existir outramente. Tornamo-nos "nós" de uma emergência que equação colonial alguma alcança; tornamo-nos "nós", porque a emergência de tudo que criamos e tocamos arranha as zonas ontológicas distintas, ao mesmo tempo em que ressoamos por todas elas e, sobretudo, buscamos ultrapassar todas elas. Eis a nossa melodia que não se resume à técnica sonora, embora utilizemos as técnicas disponíveis e as recriemos.

O olho não se restringe à experiência subjetiva e à representação da coisa vista ou às suas possíveis capacidades de representar e/ou não representar algo. Quando inventamos possíveis sem abolir as estruturas imaginativas e criativas do mundo tal como o conhecemos, toda contingência já vem capturada. É naquilo que o sentido de possibilidade nem foi manifestado como acessível - o impossível - que aprendemos a tramar as possibilidades que nos retiram de toda localidade deste mundo e, assim, anunciamos a plenitude das coisas. Porém, o olho não é fenomenológico nem desconstrutivista. Ele nem se prende ao existencialismo da coisa nem a sua desconstrução criativa, embora a criatividade o constitua. A ideia de fenômeno vem sendo um problema, quando buscamos ultrapassar o cognoscível e o pictórico naquilo que ambos não dão conta de ver, descrever e interpretar. Como nos adverte Moten:

De fato, fenômeno é provavelmente uma palavra enganosa, uma vez que as restrições de semelhança estão ligadas à insistência de sua numenalidade (em alusão à teoria kantiana do mundo numenal), uma numenalidade marcada pela resistência da semeIhança à explicação ou, mais precisamente, ao emprego na tarefa de explicação. Algo escorrega pelas fendas ou cortes da iconicidade, semelhança, metáfora, de tal forma que o pensamento opera na ausência de qualquer correspondente real e manipulação translacional do conceito de semelhança interna ou relação interna pictórica. ${ }^{5}$

A questão para Moten vem de como descrever a experiência com o signo e, amarrada nessa questão, está a suposição wittgensteiniana de uma lógica estrutural interna dos signos, mas que a descrição, em lugar da explicação dessa lógica, assume a tarefa de cortar, no espaço entre expressão e significado ou entre significado e referência, sem continuar a ser uma 
experiência do significado. Esse é o caso de uma experiência da passagem ou corte que não pode ser explicada, porque aquelas formulações sobre as quais as nossas explicações costumam ser ordenadas - ações de fala à distância; comunicação entre espaço e tempo separados; duplos do que vemos e o que nos olha, naturalizados por pretensas cisões e modulações que só coram certa rigidez; destinos antifenomênicos que colocam os caminhos das imagens novamente no destino fenomenológico - são, para o autor, elas próprias profundamente danosas. $\mathrm{O}$ autor aposta em uma estética visionária:

\begin{abstract}
Como a estranha correspondência entre partículas distantes, como os mistérios da comunicação com os mortos (ou com a tradição), as paradoxalmente eletivas e imperativas afinidades do e dentro do conjunto devem ser descritas dentro de uma improvisação radical da própria ideia de descrição (dentro e através da sua relação com a explicação), que nos afastaria da semelhança oculta e ontologicamente fixa para a anarquização da variação, mas não variação de (sobre) - e, assim, com (out [-from-the-outside]) - um tema. Na constelação de significados, compreensão, música, frase, sentimento, variação e imaginação, podemos falar novamente de iconicidade, uma segunda iconicidade, não como a significação de uma estrutura lógica partilhada, mas como uma espécie de percepção de um aspecto, que permite um sentido temporal e ontológico, um sentido fora do temporal e do ontológico, onde vemos - tanto factual como conceptualmente, estática e transitoriamente - entidade e variação, cada uma sem tema. ${ }^{6}$
\end{abstract}

A interpretação não diria mais respeito a uma hermenêutica sobre/com a coisa, mas a um improviso radical com a percepção e a sensação. Quando nos valemos da interpretação como um trabalho sobre os signos, em que as vidas negras estão às voltas, ela só alcança as modulações dos fantasmas. Ela está refém da ida e da volta fantasmagóricas que, por mais que nos informem sobre os assombros de uma sociedade, não são a força das poéticas das gentes constrangidas pelo mundo tal como conhecemos. Por mais que esses assombros incitem tais gentes a reexistirem, como nos quer ver a Sociologia Imaginativa de Gordon7, as estéticas pretas fugitivas, por exemplo, conseguem fugir e imaginar seus futuros exatamente porque improvisam na mensagem do fantasma e com esta mensagem um novo ruído. Talvez seja o assombro um mecanismo por meio do qual o conjunto nos é disponibilizado como fenômeno. Caso seja, ele se torna o suplemento da descrição que permite a caracterização radical das forças envolvidas, uma vez que "a descrição do fenômeno ou experi-

6 Moten 2003, p. 92 (tradução própria).

7 Gordon, 2008. 
ência do conjunto só é adequada se ela própria for também o fenômeno ou experiência do conjunto"8.

\section{O não conceitual}

Proponho o conceito de uma arte negra como um não-conceito, uma não formulação representacional do conceito como semelhança ou imagem. Assim, o que a obra negra explode como conceito é a emanação espectral, fantasmática de algum âmago ausente, que nos coloca na oscilação epistemológica e ontológica sistêmica entre continuidade e diferença, estruturando a semiótica de um sistema de semelhanças que subsume questões de diferença e ausência, em uma consideração pragmática de nossa distância absoluta do relativismo entre a ideia e a matéria da poética apresentada ou em execução. Ainda presas ao futurismo reprodutivo das artes, as materialidades negras materializariam o conceito de como as pretitudes são subtraídas, de como os jogos sociais são montados para que essas vidas percam desde sempre, de como continuamos o alvo dos grandes assaltos à dignidade humana, de como moradia, saúde, educação, alimentação e, sobretudo, desejo nos foram negados. Mas se dessa materialização improvisarmos outra coisa? Nesse improviso, o trágico cálculo de nossas vidas é colapsado e a equação não chega a uma semelhança entre arte e vida, tampouco a obra se torna imagem de nossas vidas. Há uma improvisação na oposição entre o existencial e o político, tanto como nas tentativas de conjurá-los em uma só coisa.

Nas condições de possibilidade desse conjunto de coisas impossíveis, as pretitudes vão ganhando materialidades; essas matérias nascidas do roubo legalizado e de todas as outras subtrações devoram o signo da própria subtração que nos acompanha, sem gerar produto pelas nossas faltas, sem desejar pelo nosso não-direito ao desejo. Então a produção em nossos processos criativos em que a criação é sempre multidimensional consiste em um trabalho não alienado com o conjunto de signos da governança. A improvisação desvia da resposta libertadora que essa arte pode oferecer, sem negar a resposta, e ultrapassa a semelhança com o trágico que anseia por essa resposta. Artistas ansiosos/ansiosas por representatividade e por combater mortes em favelas, por lutar contra o encarceramento em massa, contra os assédios às mulheres e as violências às crianças somente 
improvisam quando suas obras deixam a resposta e o que a chama sem oposição e sem unidade entre eles. Deixamos que o corte atravesse esses polos e, nesse local de falha, que a nossa condição de possiblidade reserve vida. Longe de ser a diferença calculada pela governança, estamos mais próximas da falha de mapeamento, da incapacidade de um referente normativo vir novamente a nós como ideologia de ascensão ou como simples parâmetro para nossas negações frente ao próprio mundo. Não estamos mais presas a locais de fala, ocorre que estamos noutros jeitos de estar vivo/viva em que o mundo não nos mapeia mais. Já o local de fala retoma a experiência subjetiva e as estruturas de dominação para a compreensão de que posição coletiva alguém enuncia, com sua existência ou mesmo com o sentido de não existência (não humano, não normal, não desejável, etc), perante as estruturas de dominação. As materialidades negras improvisam no local de fala, de modo que a matéria refaz o tecido infinito da escuridão: eis a comunhão negra não-local. O "em comum" não é uma unidade apaziguadora ou redentora, mas sim uma aliança do fractal, de forças infinitas e gerativas. Somente pelo "em comum", nos realinhamos com o cosmos, somos capazes de sentir a implicância profunda das coisas. Não estamos "em comum", simplesmente porque passamos por uma mesma situação de violência como o racismo às vidas não brancas, a homofobia aos homossexuais, a transfobia às gentes trans, o machismo às mulheres etc. Estamos, porém, "em comum", porque em todo conjunto reencontramos um pertencimento mais profundo que ultrapassa a resposta ou a luta contra a violência que nos seja comum. $\mathrm{O}$ "em comum" é vital para qualquer política do comum, mas não se resume a ela.

\section{Redes cósmicas e tecnologias ancestrais}

As tramas da rede cósmica são uma tecnicidade aparente na oscilação entre singularidade e diferença, singularidade e totalidade. A questão, porém, é que muitas tecnologias ancestrais, ao improvisarem a oposição da Terra e do ser, da imanência e da transcendência, decretam uma diferenciação não humana - um corte no holismo que poderia unir partes diversas em um todo fechado -, fazendo universo e ser em expansão e contenção, sem dentro e fora, mas com corpo e espírito. Há jeitos de distinguir as coisas, os seres e as forças sem se valer de ontologias separatistas, tampouco de junções híbridas. É aí que todo arcabouço moderno-colonial de purificação e mesmo de simetria vacila - ao lidar com essas tecnologias que nunca são as mesmas, mas carregam essa questão.

Alguns dos antigos povos nômades das Américas que atravessaram o que hoje chamamos Brasil não promoviam um apagamento de sua presença 
no território deixado, não intentavam desaparecer dali, mesmo decididos a saírem dali. Era um desaparecimento parcial que instaurava uma descrição premonitória do exterior de onde se vive/vivia, traçando uma espécie de círculo quebrado na Terra. Era a cartografia profunda do mundo que esses povos traçavam e com elas iam mais uma vez delineando as paisagens do próprio mundo. Não havia desterritorialização, pois como já tinha pensado Fanon ${ }^{9}$, ao compor as noções de despossessão (existencial/material) e máquina territorial, tais noções dizem de um processo de violência que condena o povo colonizado em sua própria terra e o impossibilita de pertencer ou sentir pertencer a ela. No contexto fanoniano, a máquina territorial é uma máquina colonial, uma engrenagem desterritorializadora da dignidade das vidas codificadas como negras e indígenas ${ }^{10}$, automaticamente, descodificando-as como humanas.

Foi pelo exercício da desterritorialização que as diásporas pretas do Atlântico ocorreram: fazer as pretitudes africanas falarem alguma língua que não era a sua, fazê-las assumirem alguma religião que não a sua, fazê-las seguirem relações sociais em que eram constantemente o ser excluído de humanidade; em suma, impor às vidas africanas em suas diversas manifestações serem $O$ Negro, uma designação outorgada pela brancura colonial. Nesses casos, o processo de fazer uma cartografia com o mundo para esses povos escravizados diz de um improviso na própria rede de violência por eles sofrida. Como não serem gentes despossuídas de sua terra se já estavam acorrentadas, mal alimentadas, trancafiadas em porões sujos de navios? Como refazer um círculo quebrado com o mundo sob essas condições? Ou como vidas que foram partidas podem encontrar um sentido de união pela própria quebra em terras que as excluem de toda dignidade? Desde ali, naqueles porões sujos, os meus e as minhas ancestrais operaram uma premonição com a própria escuridão. Era preciso viver e nós vivemos, porque eles e elas viveram. Nas colônias, todo sensível negro se inventou outramente de vidas partidas que se encontraram umas nas outras, de vidas-áfricas que, arrancadas de seus respectivos solos rumo as Américas, nunca perderam a capacidade de ser terra, de ser mundo em uma relação da qual a hapticabilidade era uma força.

9 Fanon, 1968.

10 Uso a palavra indígena em itálico para enfatizar que, no que tange aos povos das Américas, essa designação foi mais uma das múltiplas violências impostas por certo mundo em sua invasão colonial às populações originais viventes no continente. 
Hapticabilidade, a capacidade de sentir através dos outros, para que os outros sintam através de você, para que você sinta que eles e elas sentem você, essa sensação do enviado e da enviada não é regulada, pelo menos não com sucesso, por um estado, uma religião, um povo, um império, um pedaço de terra, um totem. Ou talvez pudéssemos dizer que estes são agora recompostos na esteira do embarcado e da embarcada. Sentir os outros é desmedido, imediatamente social, entre nós, nossa coisa, e mesmo quando nós recompomos a religião, ela vem de nós, e mesmo quando nós recompomos a raça, nós a fazemos como mulheres e homens de raça. Recusamos estas coisas, primeiro recusamo-las, no contido, entre os contidos e as contidas, deitados juntos e deitadas juntas no navio, no vagão, na prisão, no albergue. Pele, contra à epidermalização, sentidos tocantes. Juntos e juntas, tocados uns aos outros e tocadas umas as outras foi-nos negado todo sentimento, negado tudo o que era suposto produzir sentimento, família, nação, língua, religião, lugar, lar. Embora forçados e forçadas a tocar e a ser tocados e tocadas, a sentir e a ser sentidos e sentidas nesse espaço de nenhum espaço, embora nos foi negado o sentimento, a história e o lar, sentimos uns nos outros e uns pelos outros, umas nas outras e umas pelas outras. ${ }^{11}$

A hapticabilidade propicia o olho que vê e não pode ser visto por quem não desenvolveu uma "objetividade corporificada" ${ }^{12}$, uma maneira de efetivar a vida no invisível aos poderes reguladores que separam abstrato e matéria. Não é o caso também de o olho ser um bem adquirido por certas economias simbólicas que promovem "a distinção"13, no sentido sociológico, que tenta explicar por que determinadas gentes estão aptas a acessarem certas posições e coisas do mundo e outras não, via hierarquias e sistemas de economia simbólica. Ao empregar a objetividade, tenho em mente não seu significado clássico tão frequente nas ciências, mas sim uma maneira de desamarrar as distinções entre sujeito e objeto, prática e teoria, temporal e espacial, epistemológico e ontológico, compreendendo-a como uma recusa às fixações representacionalistas, culturalistas e discursivas das ideias e das coisas sob e sobre os corpos. E mais: não intento uma correlacionalidade entre os corpos e as demais matérias do universo, sob alguma espécie de denominador sensível comum. Pressuponho que as relações existem, mas elas existem na medida em que a Relação de que fala Glissant ${ }^{14}$ também existe, continua e continua, menos porque a totalidade se encontra impossível de ser alcançada e mais porque redesenhamos o total pela infinitude, ao mesmo tempo em que as nossas vidas foram quebradas. A Relação não se resume às relações sociais e culturais. Ela não permite ser

11 Moten, 2013, p. 98 (tradução e acréscimo do feminino próprias).

12 Gadelha, 2019, p. 22.

13 Bourdieu, 2007, p. 09.

14 Glissant, 1995. 
vista como a correlacionalidade de uma relação sob a outra, ela nega toda sobrecodificação, mas ela está lá presente em nossas maneiras de nos relacionarmos com outras gentes, seja mesmo para ser negada.

Vemos muito bem que há relações, mas não vemos a Relação, no que concerne a expressão cultural das comunidades. Entretanto a Relação está aí presente, ela existe. Isto significa que quer eu queira, ou não, que eu aceite ou não - sou determinado por um certo número de relações no/do mundo. ${ }^{15}$

De volta ao caráter nômade de algumas gentes, o movimento do mundo passa a acontecer por meio da Relação que age em todas as relações. $\mathrm{O}$ segredo vem à iminência de ser revelado: estamos sempre em mudança e... Ocorre que nenhum povo nômade nunca teria se juntado ao universo, tão simplesmente como possa parecer, e, se alguma vez o tivesse feito, não teria lugar para ninguém migrar refazendo os cosmos. As gentes nômades desenham em corpo e espírito um círculo quebrado da mesma forma que o universo toca um círculo quebrado. Não é que tudo retorne a um estado originário nem que retorne de maneira que o círculo permaneceria completo e impossibilitado de toda origem. Ocorre que o retorno está sempre modificado, uma vez que a mudança corresponde à única permanência. Toda mudança radical vem da improvisação de autenticidade e totalidade pelo corte que permite a expansão infinita. Se formos tentar compreender isto por teorias científicas, logo nos aproximaríamos da teoria de Barad ${ }^{16}$ de que o universo opera por cortes de causa-efeito, dentro de um realismo agencial da matéria.

Falar em tecnologias ancestrais do "em comum" foge de nos levarmos facilmente a perceber gentes pela lógica dos "sujeitos-efeitos" de redes discursivas e/ou de máquinas-desejantes. "A teoria dos 'sujeitos-efeitos' pluralizados dá a ilusão de um abalo na soberania subjetiva, quando, muitas vezes, proporciona apenas uma camuflagem para esse sujeito de conhecimento"17. A teoria spivakiana compreende que as chamadas teorias pós-estruturalistas tendem a camuflar a posicionalidade particular de certos sujeitos do conhecimento, refundando-o como o local do sujeito universal:

15 Glissant, 1995, p. 37 (tradução própria).

16 Barad, 2017.

17 Spivak, 2010, p. 25. 
Embora a história da Europa como Sujeito seja narrada pela lei, pela economia política e pela ideologia do Ocidente, esse Sujeito oculto alega não ter 'nenhuma determinação geopolítica'. Assim, a tão difundida crítica do sujeito soberano inaugura um Sujeito. ${ }^{18}$

As pretitudes no Brasil e creio que as demais do planeta, contudo, não constituem o efeito de tecnologias modernas, embora o personagem Negro, criado por certo mundo como o seu contrário, seja sim um efeito dela. Ocorre que essas tecnologias só nos vêm como "o estranho" e nunca realmente pelas maneiras como de fato existimos e nos manifestamos nas relações que traçamos, inclusive as relações com essas tecnologias. Os efeitos de uma sociedade pós-industrial, bem como os da industrial e, muito antes, os da mercantil, foram feitos para aquelas vidas que ressoam pelo controle e estimulação de toda técnica moderna. Não somos oriundos dela; somos, sim, os mundos que ela codifica como estranhos, porque primeiro nos descodificou de qualquer possibilidade de pertencimento ao mundo.

As tecnologias do capital em suas mais variadas versões convergem com a logística da escravidão que serviu de algoritmo para reprodutibilidade de outros modos de espoliação. Os efeitos dessa tecnologia têm todos os seus fluxos assombrados por fluxos de morte. O signo do capital é o signo cadavérico de sociedades, culturas e vidas despedaçadas em que as vidas pretas africanas e dos povos originários viventes nas Américas foram tratadas como matérias desapropriadas de humanidade. Porém, a partir do contato moderno-colonial com a Europa, as gentes tanto das Áfricas como das Américas passaram a desenvolver tecnologias exatamente de como se manter gente viva perante o massacre de suas vidas. Por um lado, é uma operação sempre múltipla e inacabada de improvisar dentro e por meio das próprias tecnologias modernas, por outro, é o ato de manter vivas as sabedorias ancestrais que, diante do peso da civilização branca, faz da técnica um corte à própria técnica civilizatória.

Ao estarem em condições impossíveis de serem livres, essas gentes passaram a sinalizar as fronteiras vivas do mundo. A colonização, em sua empreita de invasão, conquista e expansão, ao condenar a gente colonizada em sua própria terra, quando não simplesmente a traficava por outras terras ou a exterminava de modo direto, fez com que essas gentes passassem mais do que viver entre um mundo originário e outro imposto. Mais do que habitar 
duplos de tempo e espaço, aquelas gentes chamadas de Negro e de Indígena passaram a ser signos dos sistemas de classificação e separação, cujo significado lhes foi violentamente imposto. Isso me lembra uma afirmação de Mitropoulos: "a fronteira não é nada senão um sistema de classificação"19. Embora a história de várias fronteiras seja muito mais complexa, o salto histórico consequente é que o extrativismo em terras indígenas e o tráfico negreiro serviram de laboratório para o controle sobre duas coisas: os movimentos legítimos de pessoas e dinheiro. Sem fazer determinismo do capital às raças ou das raças ao capital, o que notamos, nos últimos séculos, é um processo de logística profundo que gera tanto a reprodutibilidade do capital como da ficção racial sem que ambos possam ser vistos em zonas distintas. Essa indistinção é o que produz a governança. O Atlântico funcionou como uma grande rede para essa logística, bem como as rotas de fuga das gentes escravizadas improvisavam a rede contra a sua própria logística de morte. Já as diásporas de povos originários por dentro do continente americano, desde as já efetivadas antes da chegada das caravelas até as disparadas como modos de fugir da colonização, foram tecendo os novos fios de outra rede, uma rede cosmosensória ${ }^{20}$ em que certas tecnologias ancestrais eram o que permitiam a própria expansão da rede. Aquele Brasil que as gentes colonizadoras europeias encontraram e com que se maravilharam só existiu, porque sempre houve movimentos dos povos originários dentro das Américas, em que certa Relação era efetivada agenciando vários e singulares modos de relações. Como informou Krenak, no episódio As Guerras da Conquista da série Guerras do Brasil.Doc (BR, 2019) ${ }^{21}$, a chamada Mata Atlântica, encontrada em territórios brasileiros e que, em sua abundância de fauna e flora, destoa dos seus entornos, foi oriunda de longínquos processos de migração de populações originárias que por ali passaram e consigo trouxeram coisas e saberes (sementes, ervas, raízes, modos de cultivar, maneiras de caçar, rituais de cura com o universo etc), transformando aquela região em uma espécie de "jardim do mundo". Sem os seres designados indígenas, essa chamada Mata Atlântica possivelmente não existiria.

Dito isto, a logística da governança revela como o "devir-negro do mundo"22 opera, tornando superficiais as separações entre Negro e Branco, Branco e

19 O’Brien, 2017. p. 85.

20 Em referência a minha teoria da cosmosensoriologia. Gadelha, 2018.

21 Guerras do Brasil.Doc (2019), Direção de Luiz Bolongesi, Brasil.

22 Mbembe, 2014, p. 14. 
não-Branco, embora implicado no racismo dessas divisões. O medo racializado, ao lado das práticas de especulação financeira, se torna o que move os fluxos necropolíticos no agora, dificultando em toda parte fazermos cessar esse devir-negro, um devir que, agindo por sistemas de governança, torna inoperante compreendê-los pelas narrativas críticas das esquerdas sobre o capital. Dessa maneira, não é mais possível separar o Estado do dinheiro ou a política das finanças, ao mesmo tempo, seria uma limitação acharmos que eles seriam uma só coisa ou se transformariam nessa coisa única e terrivelmente possível. A necropolítica passa pelo tecido de toda sociedade com velocidades, multiplicidades, variações e derivações que refazem $O$ Negro aos novos apetites da governança e a governança se torna cada vez mais móvel e estratégica. Se, na prática, esses poderes reguladores estão voltados para a conversão dos movimentos em comércio ou para o controle do trabalho como parte dessa conversão, os fluxos cada vez mais ávidos em tornar certas materialidades em materialidades negras - no sentido das matérias-vida que são usadas para os propósitos da especulação, da exploração e do lucro -informam que a fuga age pelo improviso à reprodutibilidade desses propósitos e não os faz parar, utilizando-se também dos meios para redistribuir forças no sentido de que a vida continue e de que a continuidade diga sempre sobre alguma quebra com os movimentos que buscam a conversão, à maneira dos undercommons ${ }^{23}$.

\section{As fronteiras e a violência mimética}

A imagem fugitiva opera na redistribuição das forças da visão, de modo que o velho jogo extrativista de imagens em captura, tais como realizações visuais de sujeitos da supremacia racial sobre povos originários ou sobre outras gentes racializadas ou demais gentes das parcelas expropriadas, pode encontrar verdadeiras armadilhas ao próprio olhar que as "captura" e o qual pretensamente se funda como arte dialógica, inclusiva, democrática ou outra camuflagem típica do olhar colonizador. Ao contrário, não se trata de qualquer trabalho visual com essas gentes, mas de como as gentes em fuga devolvem a captura por meio de novas armadilhagens,

23 "Nos undercommons do domínio social reprodutivo, os meios, isto é, os planejadores ainda fazem parte do plano. E o plano é inventar os meios em um experimento comum lançado de qualquer cozinha, qualquer varanda dos fundos, qualquer porão, qualquer sala, qualquer banco de parque, qualquer festa improvisada, todas as noites. Esse experimento em curso com o informal, realizado por e sobre os meios de reprodução social, como o advento das formas de vida, é o que quero dizer com planejamento; planejar no undercommon não é uma atividade, nem pescar, dançar, ensinar ou amar, mas o incessante experimento com a presença futurista das formas de vida que tornam tais atividades possíveis". Moten; Harney, 2013, p. 74 - 75 (tradução e destaque próprios). 
como nós simplesmente mantemos o segredo de nossas percepções com o mundo, de modo que tudo que fornecemos ao olhar estrangeiro, desde uma máscara ou um instrumento ou mesmo uma simples pose às câmeras, enclausura o próprio movimento de ver e ser visto. "O que faz de uma armadilha uma armadilha é um estado de prisão e enclausuramento" 24 . Os olhos enxergarão nossos corpos, nossas formas, nossas cores, nossos artefatos, mas nunca nos enxergarão de fato, porque esses olhos estão impossibilitados de gerar um olho, de ver o nosso olho ou com nosso olho.

Por hora, três condições devem ser anunciadas: 1) a armadilhagem não é um programa que intencionamos reativamente, mas a imaginação radical que escapa do jogo de aprisionamento do mundo; 2) a armadilhagem não nos posiciona em um lugar do mundo, pois ela, além de indicar a retirada dos lugares formais que referenciam o sujeito como centro de sensação e percepção das coisas frente as estruturas de poder, não se encontra refém de um modo reconhecível de ser/estar no mundo; 3) a armadilhagem só se torna possível em composição profunda com as duas matrizes do infinito, o que existe e o que (ainda) não existe.

Essas três condições sabotam o roubo do que pode ser criado. Quando nos roubam, deixamos de nos ver no objeto pilhado. Sem a menor intencionalidade, resguardamos um direito ao invisível. Não traçamos alguma fronteira, apenas nos tornamos i-mapeáveis aos sistemas de classificação e, ao não obedecer ao mapa, o público dessas imagens é convidado, através do corte de uma narrativa em diferentes perspectivas, a adoptar posições críticas em relação ao espetáculo dramático do visível, no qual o desmantelamento programático da identificação com algum arquivo pessoal-social-cultural e, com ele, a desvinculação consciente de emoções dificultam as vinculações como empatia e compaixão, mostrando como elas são instrumentais não só para os apetites do futurismo reprodutivo das artes, mas também para possíveis demandas políticas vindas dos sujeitos de fora: proteção aos povos designados indígenas, lutas antirracistas em prol de gentes pretas, alianças na participação por direitos de minoridades sexuais e de gêneros. Isso acontece, porque "os fantasmas da identificação recusam-se a morrer, e tipicamente voltam a assombrar cenários envolvendo lealdade e traição e a dor e o prazer que acompanham a perseguição de 
objetos, sejam estes objetos humanos ou não humanos"25. O problema a nós ocorre se, diante do retorno dos fantasmas, ficarmos refém deles em algum embate meramente reativo.

As oscilações fantasmagóricas se alimentam de certas autorreferencialidades da dor e as reproduzem, tornando difícil para alguém conseguir escapar de seu local de subjugação ou do local de culpabilidade por privilégio. Seja alguém privilegiado/privilegiada em busca de reparação histórica àqueles vidas que foram e são historicamente subjugadas, seja alguém pertencente a essas vidas exploradas e espoliadas de tantas maneiras, a autorreferencialidade que comumente se centra na brancura e na heterossexualidade cisgênera como as posições fundantes de toda opressão colonial acaba por deixar intactas todas as logísticas profundas que fundam tais posições como hegemônicas ou que, simplesmente, as legitimam, permitindo a sua assombrosa continuidade. A mudança radical não ocorre, porque nos prendemos novamente aos objetos que questionamos e que tentamos ultrapassar. Por exemplo, quando lidamos com desejos coloniais, estamos numa relação profunda de mimeses que refunda antigos princípios de originalidade do que seriam a humanidade, o belo, a natureza, a normalidade, a ideia de civilização etc. No entanto, por mais que esses princípios busquem ser totalmente compartilhados, eles não o podem ser entre todas as vidas. Na colonialidade, não há partilha entre gentes privilegiadas e não privilegiadas, porque o dissenso das forças envolvidas não produz abolição das arquiteturas jurídicas, econômicas, morais e outras que sustentam o mundo tal como o conhecemos. As partilhas coloniais ocorrem em/por zoneamentos sem desfazê-los. E mais: a própria ficção racial que opera por fronteiras entre vidas vivíveis e vidas não vivíveis, refazendo todo o seu princípio em constante privilégio de certa raça, dificulta as possibilidades de compartilhamento não zoneado, porque seu objetivo nunca foi a equidade entre vidas distinguidas. $O$ desejo, como produção coletiva que legitima o Branco como o belo e o bem e que chega a levar parcelas significativas de gentes não brancas do planeta a se valerem de máscaras brancas, opera cotidianamente em processos de mimeses que, por mais individuais que pareçam, obedecem a demandas que são estruturais de sociedades inteiras. A aproximação a esses objetos, por parte de quem o acesso a eles se encontra negado, ocorre em maiores ou menores medidas de maneira traumática, uma vez que ela é simplesmente impossível de ser totalmente alcançada por parte dessas gentes. A colo- 
nialidade atual produz a ficção de alcance, camuflando o fato de que tais objetos não foram feitos para essas gentes e que simplesmente eles não manifestam as vidas dessas gentes.

De onde vem a ideia ou o desejo de manter a ética de um mundo que se faz o mesmo para todos os outros, embora saibamos que tal mundo só existe como um projeto falido? Sabemos que vem de determinadas ficções de poder, mas como essas ficções extremamente irracionais conseguem essa força de serem reproduzidas quase automaticamente, quase negando qualquer parcela de reflexão durante toda essa reprodução?

A partir da tese de Girard, voltamos a $\mathrm{Chow}^{26}$ que afirma a mimética como o próprio mecanismo ou o primeiro termo das relações culturais coletivas. Ela se encontra ciente que essa observação não apologética da iteração ou repetição sem sentido do comportamento humano pode ser desconcertante, pela simples razão de que se recusa a idealizar ou a pretender a humanidade, individual ou coletiva. Ocorre que a mimeses não é um jogo binário entre o referente e a cópia, mas um processo criativo que sempre refunda a originalidade que, em si mesma, não existe. As ficções de poder refundam certa raça como a humana por excelência, quando sabemos que essa raça originalmente correta/normal/+evoluída não existe; essas ficções dizem ser a heterossexualidade cisgênera a norma de sexo/gênero/ sexualidade a ser reproduzida, quando sabemos que não existe um princípio de originalidade para as identificações do ser e os desejos entre corpos. Todavia, a colonialidade age no mais profundo dos corpos por uma mimese a objetos do desejo legitimados por ela própria.

Mbembe ${ }^{27}$ chega a falar de certos objetos psíquicos do racismo para demonstrar como determinadas gentes se prendem subjetivamente a elementos da ficção racial, mesmo quando tentam questioná-la ou aboli-la, como foi o caso das etnologias que, ao afirmarem a pluralidade de culturas, o relativismo de modos de ser e agir entre sociedades e as diferenças históricas entre grupos humanos, refundaram a ficção racial por meio dessas diversidades, deixando nítido que o Outro da antropologia moderna consiste em mais um objeto psíquico do racismo do Ocidente Branco. De onde viria essa necessidade de ter um Outro, de saber de onde ele vem, 
o que ele pensa, como ele se veste, ritualiza, come, dança, sexualiza etc? Ora, vem da separabilidade e da determinabilidade ${ }^{28}$ que fundamentam a ficção racial e a antropologia mesmo, quando passou a questionar as separações entre eu e outro/nós e eles, continua mantendo esse projeto de interpelar certas vidas de maneira a sempre amplificar o velho "extrativismo cognitivo", que é nada menos do que uma das engrenagens da maquinaria colonial. As chamadas autoetnografias podem cair facilmente na cilada de que estariam se contrapondo a tudo isso, quando acreditam que essas separações estariam fraturadas ou mesmo inexistentes, já que as vidas outrora tornadas o outro seriam agora as responsáveis diretas pela produção do conhecimento etnográfico. Ocorre que não raramente essas autoetnografias refazem os velhos modelos da sobrecodificação, voltando-os para si mesmas, ou seja, não há mais a separação nítida entre nós e eles nos planos narrativo e descritivo diretos, mas permanece todo o desejo de interpelação de uma diferença dessa vez buscada das mais diversas formas, na vida daquelas gentes que se posicionam como as autorrealizadoras do empreendimento antropológico. Então esses trabalhos acabam por exercer uma outra maneira de violência mimética no plano do que seria uma crítica aos modos de fazer antropologia. Isso não significa negar a importância de construir outras ontoepistemologias pelas margens, mas sim de que, nessas produções, a logística de antigos esquemas coloniais não seja novamente atualizada. É contra essas atualizações, por exemplo, que temos vários trabalhos autoetnográficos de gentes quilombolas, afrodiaspóricas e indígenas, dentre outras. Então o problema não está em fazer autoetnografia. Operar com fronteiras sejam elas quais forem só permite manter a vida à medida que encontramos condições vitais de reimaginarmos as rotas.

\section{Visibilidades anticoloniais}

Podemos propor uma crítica realmente anticolonial a partir das relações sobre arte, em especial entre arte e armadilha, no sentido além daquele conferido por Gell ${ }^{29}$ em sua teoria da agência. Para tanto, é necessário reposicionarmos a importância das ideias de intencionalidade e causalidade, reconhecendo seus limites em planos comparativos, até reformularmos

28 As noções de separabilidade e determinabilidade são utilizadas nos sentidos compreendidos por Denise Ferreira da Silva sobre o relato ético do mundo fixado na ficção racial. Para saber mais, recomendo a leitura de: Ferreira da Silva (2019).

29 Gell, 1998. 
uma sentença foucaultiana, a saber: "visibilidade é armadilha" ${ }^{30}$. Como podemos processar tudo isso?

A armadilha opera para que algo se torne visível ou mesmo invisível, com o objetivo de que a captura aconteça. A armadilha anticolonial vem como condição de possibilidade para que as vidas miradas como caça improvisem de maneira radical esse jogo que, por sua vez, replica a imaginação da flecha do tempo. Essa armadilha não se trata de um conceito ou uma reflexividade, mas sim de uma matéria vital para preservar a vida em determinadas circunstâncias. Ela é uma quebra. No plano das visibilidades, a quebra ocorre não por uma simples cisão do olhar, mas por condições de improviso do visual. O desejo de correlacionalidade que já parte de zoneamentos para propor acoplamentos e/ou supostas cocriações disfarça brevemente certa fobia com outras visibilidades, tentando as ver a partir de um modo de conceber o ícone que serve de referência a outros. (O que é bastante comum nos trabalhos extrativistas da antropologia e da sociologia sobre poéticas efetuadas nas cidades por grupos historicamente expropriados). Chow faz a seguinte pergunta: "É de todo possível conceber uma forma não iconofóbica de lidar com as relações sociais e visuais?"31. A iconofobia, mais do que uma aversão direta a outras visibilidades, tende a não perceber que os binarismos coloniais universal/particular, Branco/ Negro, Ocidente/Oriente, centro/margem, privilégio/precariedade, urbanidade/ruralidade, o mundo/e seus outros estão em movimentos intersticiais constantes, de maneira que a autorreferencialidade, em alguma diferença intrínseca e absoluta da construção das imagens por parte de determinadas gentes, pode facilmente amargar uma suposta diferença intrínseca dessas mesmas gentes. Isso, por sua vez, produz uma moralidade das imagens que espelharia aquela da pessoa imaginada como coletivo. Daí surgem perguntas essencialistas/esvaziadas/objetificadas do tipo: qual o real cinema negro? Ou qual o verdadeiro cinema chinês? Ou mesmo o que seria uma imagem não ocidental? A fobia pelo diverso que move essas perguntas esquece de como seriam possíveis os cinemas negros, os cinemas chineses ou simplesmente a experimentação das condições de possibilidade para a produção de imagens não ocidentais e não coloniais. Essas condições de possibilidade tramam fugitividades, pois correspondem ao que permite o segredo de como fazer imagens, às quais não se

30 Foucault, 2005, p. 166.

31 Chow, 2007, p. 148 (tradução própria). 
deixariam capturar pela colonialidade, mesmo elas sendo fabricadas ali com todo o aparato colonial do mundo. Não trataríamos mais de buscar a correlacionalidade por distinção para traçar semelhanças ou manter diferenças, banalizando histórias.

A banalização sobre certas ancestralidades cria um despojamento ou versão de purificação que procura reviver um certo antes - antes do início da colonização, antes da perda da inocência - que agora tem uma estreita afinidade entre as convenções de despojamento dos serviços e bens da sociedade capitalizada e a reflexividade mediatizada das imagens de origem. Isso produz uma gente espectadora que não completa esse jogo inacabado que se passa na vida, mas que consiste num jogo que se refaz sempre pelo chamado à incompletude. Esta reflexividade, ao mesmo tempo cativa de raízes e das logísticas da governança, tem que a primeira captura testemunha antes uma neutralização das possibilidades utópicas dessas gentes sob a forma de "apatia espectral"32. Além disso, as revelações extremas de determinada crítica anticolonial no coração de quem foi e de quem continua sob o peso da colonialidade podem ser inúteis se essas revelações deixarem de significar a mudança. O projeto de algum estranhamento para com o mundo tal como o conhecemos, concebido como se fosse para nos fazer suspender o sentimento corporificado, como piedade e medo, e desaprender os hábitos identificatórios com a normatividade que acompanham essas histórias, voltando-se para uma mesma história, a história da diferença em que o futuro só é imaginado por esse enclausuramento de si próprio/própria a um referente, prediz uma nova ficção colonial agora sentimentalmente repassada via o peso da dominação das estruturas como responsabilidade crítica da pessoa em se autoprojetar num lugar reconhecível pelo mundo. Isso gera uma suspenção em reinventar-se por meio de uma nova maneira de atravessar o mundo. Ao contrário de uma radical imanência em que vidas poderiam fraturar a separação interioridade versus exterioridade, fabricando-se a si mesmas em conjunto com o cosmos e livrando-se de sustentar alicerces de dominação, aos quais são submetidas via subjugações diversas, a pessoa crítica da colonialidade costuma primeiro negar suas identificações com certo mundo para, em seguida, se autoidentificar contra esse mesmo mundo, realocando o jogo entre anulação e resgate como facetas de sua existência sem atentar em que momentos o jogo pode ser e é improvisado. Daí nasce a inversão do 
sentimento encarnado e da identificação em apatia ou em compaixão entre gentes que limitam suas respectivas capacidades de modificar as estruturas responsáveis pelos desenhos globais das sociedades no agora.

A ética passa a surgir como enclausuramento afetivo sendo novamente engolida pelo mundo tal como o conhecemos, porque as políticas de hapticabilidade são boicotadas pela indiferença ou por um sentimentalismo dessa crítica que não prevê o exterior. Então o sentimento de pertença de grupos minoritários no poder passa a ser capturado pelo chamado relato ético do mundo como os novos episódios da história desse relato, como as versões episódicas de desobediências política e poética que refundam a velha sequencialidade histórica marcada por avanço e retardo. Por exemplo, temos os discursos sobre o apocalipse em suas diversas versões do que seria o fim do mundo e de que mundos estaríamos falando. Precisamos sair das litanias dos fins se quisermos realmente reimaginar o futuro, mas a ideia de fim do mundo acaba por direcionar aquelas vidas excluídas do humano a uma participação na crítica apocalíptica sob a informação de que elas não pertencem a esse humano. Isso faz com que tais minoridades se fechem em um sentimento de compaixão entre si, por serem excluídas das preocupações sobre o humano, assim como gera uma apatia delas em relação ao fim do planeta.

Mais do que negar uma participação no relato de salvação do mundo que não inclui de fato as minoridades, é o caso de apostarmos em produzir futuros nesse movimento distópico, futuros que permitam que elas continuem a atravessar os seus e os demais fins do mundo. Trata-se de lidarmos com ideias que, como diz Krenak, seriam "ideias para adiar o fim do mundo"33. Aí que a armadilha se revela importante, pois ela pode dificultar, transformar e redirecionar noções corriqueiras sobre captura das vidas a sempre um mesmo projeto falido de mundo.

Em transmutação do sentido de $\mathrm{Chow}^{34}$ sobre a armadilha como um índice

33 “Nosso tempo é especialista em criar ausências: do sentido de viver em sociedade, do próprio sentido de experiência da vida. Isso gera uma intolerância muito grande com relação a quem ainda é capaz de experimentar o prazer de estar vivo, de dançar, de cantar. E está cheio de pequenas constelações de gente espalhada pelo mundo que dança, canta, faz chover. O tipo de humanidade zumbi que estamos sendo convocados a integrar não tolera tanto prazer, tanta fruição de vida. Então, pregam o fim do mundo como uma possibilidade de fazer a gente desistir dos nossos próprios sonhos. E a minha provocação sobre adiar o fim do mundo é exatamente sempre poder contar mais uma história. Se pudermos fazer isso, estaremos adiando o fim". KRENAK, 2019, p. 27.

34 Chow, 2012. 
de um tipo de interação social conjuntamente fabricada sob uma divisão do trabalho desigual, responsável por engendrar o movimento de um novo processo que se torna, estritamente falando, inacabado, indeterminado e escapadiço das intenções e das inteligências do desenho da própria armadilha, proponho pensar a armadilha como aquilo que efetivamente frature os sistemas de inteligência e transferência de responsabilidades da governança sem replicar a sequencialidade entre quem ou o que caça e quem ou o que seria o alvo. O conhecimento deste artigo por meio das armadilhas, no que tange às obras de arte, ultrapassa a concepção da obra como apenas uma armadilha que insiste em confrontar alguma espécie de hierarquia entre uma intenção artística e a captura da audiência. Esse jogo entre intenção e captura é o que indica a relação entre caçador/caçadora e presa, mas o conhecimento armadilhado, nesse jogo, o redireciona de maneira a tornar possível a redistribuição de forças dessa mesma hierarquia, através da experiência das vidas a serem capturadas. Então as posicionalidades afetivas são novamente reposicionadas, rumo a novas condições de possibilidade que deslizam umas sobre as outras, de modo a emaranhar mobilidade com espacialidade - rotas - e fuga com captura.

A armadilha, tal como proponho, corresponde a um plano fugitivo que permite à presa armadilhar o que impediria ou circunscreveria a sua própria rota de fuga, ao mesmo tempo em que ela refaz o mapa que desenha a própria armadilha. A visibilidade seria a de alguma fugitividade que a armadilhagem contra a própria armadilha instaura, reservando à presa a capacidade de não ser consumida pelo jogo que, a princípio, intenta aprisioná-la em certos estados afetivos, simbólicos, históricos etc. Isso se torna possível, porque quem não se destituí de sua história e de sua obra de arte como armadilha pressupõe que esta história particular exista, já que a negação da história particular impossibilitaria as condições de possibilidade da armadilha em seu poder de redistribuir as forças responsáveis pelas separabilidades e determinalidades sobre arte e vida, arte e não arte, obra de arte e artefato, caça e presa, chamado artístico e resposta afetiva.

Assim, a obra não tem um segredo a priori escondido nem se deixa ver exclusivamente pelas formas que apresenta. Ela só existe e exibe visibilidade em um processo inacabado com o mundo e, nesse processo, o segredo é forjado. O segredo que diz do invisível, ou seja, do sentido de fugitividade armadilhado com a obra que reproduz o círculo quebrado da vida. Isso destoa de dizer que ela reivindica alguma autonomia de inteligibilidade e de sensação, de representação e de a-significação, de parte e de totalidade, de diferença e de singularidade. Embora essa minha perspectiva 
não seja exatamente uma proposta sobre "reflexividade transmedial"35, eu me aproximo de pensar como um processo pelo qual o meio artístico se torna autoconsciente, no sentido de ter uma maior consciência da sua própria atividade, capacidade e vulnerabilidade. No entanto, trato de uma autoconsciência menos diretiva e mais fractal, já que toda fuga age imprevisível e inacabadamente. Pensar a visibilidade como armadilha tem menos a ver com a produção de um visível que captura sentidos da visão e mais com os jeitos como as materialidades tornadas negras pelas logísticas da governança, no que tange aos trabalhos em arte, podem produzir conhecimentos sensíveis, cognoscíveis e outros que armadilhem o jogo presa-caça. Trata-se de colapsarmos o jogo da subtração de nossas vidas e produzirmos além da quebra novas constelações do que seja arte.

\section{Conclusão}

Por não se resumir ao plano das relações históricas e sociais, o olho indica como a Relação faz um tipo de conversão por cosmovisão em que o espaço e o tempo estão unidos como espaço-tempo (próximo ao sentido quantum da física) de uma materialidade infinita em condições de representação, sensação e, sobretudo, mudança. As forças subjacentes daquelas vidas tornadas à escuridão do mundo são convocadas por um chamado de frequências imaginativas que não permitem mais alguma temporalidade da passagem do ver ao ser visto. Isso produz o sentido de escuridão da fuga, porque a escuridão, nesse caso, não obedece às cenas de autorrealização do humano sob o mundo, típicas das visões supremacistas do planeta. $\mathrm{O}$ olho em seu poder de quebra não opera por aquilo que Wright denomina de "a passagem do meio" ${ }^{36}$, ou seja, uma série de narrativas que colocam luzes e sombras em planos de sequencialidade e determinabilidade, cujo exemplo comum é o Big Bang, o único ponto a partir do qual a escuridão supostamente se expande para fora, formando as nebulosas brilhantes do universo. Wright ${ }^{37}$ propõe compreender a escuridão como não derivativa nem iniciática de uma passagem média, uma vez que esta última orienta a negritude, prendendo-a a um único evento em uma ideia de que o tempo sempre se move para frente, linearmente e que esse movimento para frente é determinante do progresso e, consequentemente, de sua suposta

36 Wright, 2015, p. 04 (tradução própria).

37 Wright, 2015. 
importância. É esse tipo de narrativa que fomenta noções lineares em que a escuridão passa a ser percebida pelas capacidades herdadas do lluminismo, pelos cânones de obediência e desobediência, tais como aqueles dos relatos que sequenciam os marcos da escravidão às rebeliões para a desobediência civil. Esses relatos são facilmente mistificados, porque nos propiciam, ao mesmo tempo, um arquivo de desafio e os repertórios da elevação coletiva.

O problema é pensar as materialidades negras sem compreender o que está armadilhado nesse jogo de emancipação e fracasso inevitáveis, como se fosse possível sair da escuridão do mundo, atravessar a grande noite da história rumo às luzes, pois tais ideias de ascensão negam que o trabalho das vidas dessas materialidades permanece em luta complexa e difícil em que a conquista assim como a perda de direitos não podem ser presumidas por narrativas fáceis de vitórias e fracassos. A visibilidade por essa ideia de escuridão não armadilha o jogo de sombras e luzes no qual a escuridão nunca foi determinada pelas pretitudes, de modo que ela continua como uma série contínua de reações em rede ao racismo. Essas cenas de progressismo se alinham a toda má sorte de outras narrativas dominantes, tais como o machismo, a homofobia, a transfobia e outras, negando que há constelações inteiras de escuridão entre dominação e subjugação, servidão e desobediência, reprodução e invenção. A escuridão se expande infinitamente por múltiplas direções, tal como na física quântica, quando teorizam o espaço-tempo como curvado, dobrado, esticado em múltiplas direções. Penso como Wrigth que a física quântica nos permite ver a escuridão como multidimensional: dimensões e extensões se fazem por múltiplas linhas do tempo e não por apenas uma única linha que daria conta mesmo daquilo que seriam as insolências da matéria. Aí que as materialidades das pretitudes são materialidades negras, não mais exclusivamente pelas forças do "devir-negro do mundo", mas por uma série de constelações em quebra da passagem pelos polos do brilho e da opacidade, em que os fenômenos que atravessam essas materialidades seguem acima, abaixo e do lado, dobrando-se e curvando-se sempre em novos fenômenos. As relações que estes mantêm entre si e com outros predizem uma relação mais profunda, na qual as materialidades negras em seu poder de ver e serem vistas existem umas nas outras e umas pelas outras, tornando-se invisíveis a todos os olhos que não fazem parte de sua profecia infinita.

\section{Bibliografia}

BARAD, Karen. Performatividade Pós-Humanista: para entender como a matéria chega a matéria. Revista Vazantes, Fortaleza, v. 1, n. 1, p. 07 - 34, 
2017.

BOURDIEU, Pierre. A distinção: crítica social do julgamento. São Paulo/ Porto Alegre: Edusp/Zouk, 2007, p. 09.

CHOW, Rey. Entanglements, or Transmedial Thinking about Capture. Durham/London: Duke University Press, 2012.

. Sentimental fabulations, contemporary Chinese films. New York: Columbia University Press, 2007.

FANON, Frantz. Pele negra, máscaras brancas. Salvador: EDUFBA, 2008. . Os Condenados da Terra. Rio de Janeiro: Civilização Brasileira, 1968.

FERREIRA DA SILVA, Denise. A dívida impagável. São Paulo: Oficina de Imaginação Política e Living Commons, 2019.

FOUCAULT, Michel. Vigiar e punir: nascimento da prisão. Petrópolis: Vozes, 2005.

GADELHA, José Juliano. O Sensível Negro: rotas de fuga para performances. Revista Estudos da Presença, Porto Alegre, v. 9, n. 4, p. 01 - 24, 2019. - COSMOSENSORIOLOGIA: Rotas Para Uma Metodologia Fugitiva Em Artes. Revista Vazantes, Fortaleza, v. 2, n. 2, p. 170-189, 2018.

GELL, Alfred. Art and agency: an anthropological theory. Oxford: Clarendon, 1998.

GLISSANT, Édouard. Introduction à une poétique du divers. Móntreal: Presses de l'Université de Móntreal, 1995.

GORDON, Avery F. Gosthly matters: Haunting and the sociological imagination. Minneapolis: University of Minnesota Press, 2008.

KRENAK, Ailton. Ideias para adiar o fim do mundo. São Paulo: Companhia das Letras, 2019.

MBEMBE, Achille. Crítica da razão negra. Lisboa: Antígona, 2014.

MOTEN, Fred. In The Break: the aesthetics of the Black radical tradition. Minneapolis: University of Minnesota Press, 2003. 
MOTEN, Fred; HARNEY, Stefano. The undercommons: fugitive planning and black study. Wivenhoe, UK/New York: Minor Compositions, 2013.

O'BRIEN, Sean. Border, Theory, Contract: An Interview with Angela Mitropoulos. Public, Bristol, v. 28, n. 55, p. 84 - 92, Jun. 2017.

SPIVAK, Gayatri. Pode o subalterno falar? Belo Horizonte: EdUFMG, 2010.

WRIGTH, Michelle. Physics of Blackness: Beyond the Midlle Passage Epistemology. Minnesota: University Of Minnesota Press, 2015.

Recebido em 27 de março de 2020 e aceito em 26 de outubro de 2020. 